\title{
Electrodeposition of Mesoporous Ni-Rich Ni-Pt Films for Highly Efficient Methanol Oxidation
}

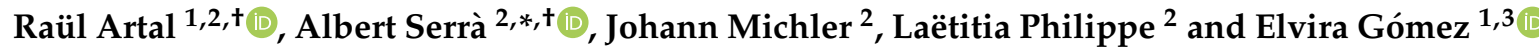 \\ 1 Thin Films and Nanostructures Electrodeposition Group (GE-CPN), Department of Materials Science and \\ Physical Chemistry, University of Barcelona, Martí i Franquès 1, E-08028 Barcelona, Spain; \\ rartal2@gmail.com (R.A.); e.gomez@ub.edu (E.G.) \\ 2 Empa, Swiss Federal Laboratories for Materials Science and Technology, Laboratory for Mechanics of \\ Materials and Nanostructures, Feuerwerkerstrasse 39, CH-3602 Thun, Switzerland; \\ johann.michler@empa.ch (J.M.); laetitia.philippe@empa.ch (L.P.) \\ 3 Institute of Nanoscience and Nanotechnology (IN2UB), University of Barcelona, E-08028 Barcelona, Spain \\ * Correspondence: albert.serraramos@empa.ch \\ + These authors contributed equally.
}

Received: 7 July 2020; Accepted: 20 July 2020; Published: 23 July 2020

\begin{abstract}
The use of soft templates for the electrosynthesis of mesoporous materials has shown tremendous potential in energy and environmental domains. Among all the approaches that have been featured in the literature, block copolymer-templated electrodeposition had robustness and a simple method, but it practically cannot be used for the synthesis of mesoporous materials not based on Pt or Au. Nonetheless, extending and understanding the possibilities and limitations of block copolymer-templated electrodeposition to other materials and substrates is still challenging. Herein, a critical analysis of the role of the solution's primary electroactive components and the applied potential were performed in order to understand their influences on the mesostructure of Ni-rich $\mathrm{Ni}-\mathrm{Pt}$ mesoporous films. Among all the components, tetrahydrofuran and a platinum (IV) complex were shown to be crucial for the formation of a truly 3D mesoporous network. The electrosynthesized well-ordered mesoporous Ni-rich Ni-Pt deposits exhibit excellent electrocatalytic performance for methanol oxidation in alkaline conditions, improved stability and durability after 1000 cycles, and minimal CO poisoning.
\end{abstract}

Keywords: mesoporous materials; electrodeposition; soft-templated electrodeposition; electrocatalysis; methanol oxidation

\section{Introduction}

As global warming's dramatic effects on ecosystems escalate due to rising carbon dioxide emissions into the atmosphere, the demand for clean renewable energies has intensified research on sustainable technologies able to replace ones dependent upon exhaustible fossil fuels [1-3]. Among the various possibilities, fuel cells and supercapacitors are promising ecofriendly electrochemical technologies for energy conversion and storage, respectively, thanks to their tremendous potential to improve energy efficiency and reduce both carbon dioxide and nitrogen oxide emissions $[4,5]$.

The transition to future energy systems has involved not only the development of efficient fuel cells with high power and energy density, as well as long-term stability, but also the use of virtually inexhaustible fuels (e.g., hydrogen and alcohols). Of the various types of fuel cells, direct methanol fuel cells (DMFCs) have received enormous attention, primarily due to the ease of manipulating and transporting methanol, a liquid substance that does not require special instrumentation or storage conditions. The other benefits of DMFCs include high energy density, high conversion efficiencies, 
negligible environmental impacts, and the ability to operate at low temperatures, the last of which significantly simplifies engineering problems [6-9].

However, using methanol in fuel cells also poses certain challenges related to unsatisfactory electrochemical performance-namely, the high anodic overpotential of methanol oxidation due to poor reaction kinetics - along with the high cost of cell components, and limited fuel cell durability $[9,10]$. The high cost derives principally from the use of noble metal catalysts and perfluorosulfonate polymer electrolyte membranes. On the long list of such catalysts studied to date, platinum is the most commonly used in DMFCs; however, its efficiency needs to be improved and its associated risk of carbon monoxide poisoning needs to be reduced $[11,12]$. To that end, nanomaterials can play a key role in developing new catalysts, whose activity intimately relates to their active surface areas (i.e., active sites) [11-16]. In general, nanocatalysts are supported on substrates with high surface area (e.g., amorphous microporous carbon powder), which afford ample surface area, sustainable porosity, high electrical conductivity, and exceptional stability. In particular, Vulcan carbon black ranks among the most widely used supports in such systems; however, its implementation requires overcoming some important limitations, including electrochemical oxidation corrosion to carbon dioxide under conditions of fuel cell operation and the resulting agglomeration, usually in the form of nanoparticles, all of which significantly decrease the system's efficiency [17-19].

The development of new catalysts for DMFCs is pivotal to reducing the use of expensive Pt. As a partial solution, incorporating lower-cost transition metals to form stable bimetallic alloys-that is, $\mathrm{Pt}-\mathrm{M}$, in which " $\mathrm{M}$ " can be $\mathrm{Fe}, \mathrm{Co}, \mathrm{Ni}$, or $\mathrm{Pb}$, among others-has proven efficient, because it not only helps to reduce Pt consumption but also enhances the catalytic activity possible due to synergistic, electronic, and/or lattice-shrinking or straining effects. However, the chemical stability of $\mathrm{Pt}-\mathrm{M}$ alloys, especially in acidic media, is generally lower than pure Pt due to the leaching of transition metals $[7,12,20]$.

Currently, one of the most widely studied alternatives to mitigate the use of Pt and Pt-based electrocatalysts is using porous materials, especially mesoporous ones, which offer high surface-to-volume ratios, use less expensive noble materials that incorporate non-precious metals, and afford more reaction sites than their bulk counterparts, which also lowers the weight of the fuel cells [15,21-23]. Mesoporous materials have been synthesized using various methods, including sol-gel, direct oxidation, hydrothermal and solvothermal techniques, micelle and inverse micelle systems, chemical vapor deposition, physical vapor deposition, electrodeposition, sonochemical methods, and microwave-based techniques. All of those processes can be included in soft-templating or endotemplating methods with surfactant and block copolymers and hard-templating or exotemplating methods - that is, nanocasting. The synthesis of ordered, uniform mesopores usually requires using template or structure directors (i.e., porogen agents) in order to define the pores [20-32].

In that context, electrodeposition has emerged as one of the most promising technologies due to its associated advantages, especially ones stemming from its low, temporary cost and the simplicity of the experimental setup used. In particular, various approaches involving electrochemical methods that use soft and/or hard templates or electrochemical dealloying have been proposed for synthesizing complex mesoporous micro- and nano-architectured catalysts. Among all of those approaches, electrochemical dealloying, which is normally based on the selective electrochemical etching of the less noble element, has been extensively used to synthesize Pt-based mesoporous architectures. Although electrochemical dealloying offers greater control over pore formation than chemical dealloying does, the strategy affords relatively low control over the size and distribution of pores and accommodates a highly limited number of materials [22,33-36]. During the past decade, electrochemical methods using soft templates (e.g., electrodeposition using surfactants, block copolymers, supramolecular aggregates, and microemulsions) have increasingly been used due to their relatively high control over pore size distribution and pore definition, simplicity (e.g., typically a one-step procedure), low cost, potential scalability, and versatility with a wide range of materials, compositions, and architectures [22]. The simplicity of soft-template electrochemical deposition allows the synthesis of mesoporous films, 
nanowires, and even complex 3D architectures of metals and alloys with large surface areas due to the creation of 3D networks $[22,25,26]$. Not all soft-template systems have the same robustness, however, for sometimes only superficial porosity is attained.

As a partial antidote, the block copolymer-templated electrodeposition has been revealed as a reliable strategy for synthesizing $\mathrm{Au}$ - or Pt-based architectures that provide uniform controllable mesoporosity on metallic substrates [21,24-26,37-39]. Even so, block copolymer-templated electrodeposition offers not only excellent control of pore size and wall thickness by varying the length of copolymer fragments, but also the final composition of deposits by adjusting the parameters of electrodeposition (e.g., bath composition, temperature, and applied potential). At the same time, because copolymers with high molecular mass are not soluble in water, using organic solvents is necessary in order to dissolve the block copolymer. Regardless of the need to introduce an organic solvent, the block copolymer concentration exceeds that of critical micelles (CMC), which promotes the formation of polymeric micelles as the porogen agent for block copolymer-templated electrodeposition. That process, in turn, allows the interaction of negatively charged metal complexes with the hydrophilic part of the micelles. As a result, the codeposition of mesoporous films can be accomplished by applying an electrochemical signal [21,24-26,37-39]. Nevertheless, its use in non-Pt- or Au-based materials is highly restricted, because only $\mathrm{Ni}$ or $\mathrm{Cu}$ films can be successfully synthesized [21,24-26,37-39]. Understanding the possibilities and limitations of block copolymer-templated electrodeposition and extending the usage to other materials and other substrates is still highly required for real applications.

Herein, a systematic study, in order to clarify the role and influence of all the solution's primary electroactive components involved in the synthesis of Ni-rich Ni-Pt well-defined 3D mesoporous networks on two typical and different substrates using block copolymer-templated electrodeposition, was performed. The results of the systematic study clarified the effect of each component of the polymeric micelle system and the influence of the electrodeposition conditions (i.e., substrate and applied potential). Tetrahydrofuran (THF), platinum (IV) $\left(\left[\mathrm{PtCl}_{6}\right]^{2-}\right)$ complex, and applied potential are crucial in mesopores definition. After clarifying the role of each component, well-ordered mesoporous Ni-rich Ni-Pt deposits were electrosynthesized and the electrocatalytic performance for the electro-oxidation of methanol in alkaline conditions was explored at room temperature. The Ni-rich $\mathrm{Ni}-\mathrm{Pt}$ films are very effective for methanol electro-oxidation as a result of the highly effective superficial area, minimal CO poisoning, and enhanced stability and durability, which are promising candidates for electrocatalysis.

\section{Materials and Methods}

\subsection{Materials}

The solid- $\mathrm{Ni}(\mathrm{OAc})_{2} \cdot 4 \mathrm{H}_{2} \mathrm{O}(>98 \%), \mathrm{Na}_{2} \mathrm{PtCl}_{6} \cdot 6 \mathrm{H}_{2} \mathrm{O}(>98 \%)$, and $\mathrm{KOH}(\geq 85 \%)$-and liquid compounds-ethanol $(>99.8 \%)$, methanol $(>99.9 \%)$, sulfuric acid $(\geq 97.5 \%)$, and tetrahydrofuran (>99.9\%) - needed to prepare the various solutions were purchased from Sigma-Aldrich (St. Louis, MO, USA). By contrast, the block copolymer polystyrene- $b$-poly (ethylene oxide) (PS- $b$-PEO) was purchased from Polymer Source Inc. (Dorval, QC, Canada). The molecular weight of each block was 63,000 for the PS and 26,000 for the PEO, respectively. All reagents were used without any prior purification and all solutions were prepared with MilliQ water from Millipore (Burlington, MA, USA).

\subsection{Electrochemical Media}

The block copolymer-templated electrodeposition of mesoporous materials is based on the use of block copolymer micelles (Scheme 1). The polymeric micelles are formed as a result of the interaction between the hydrophilic (polar) part of the block copolymer, which corresponds to the polyethylene oxide (PEO) chains, and the water molecules, as water is the predominant solvent in the system. On the other hand, the hydrophobic (nonpolar) part of the copolymer, the polystyrene (PS) units that are not soluble in aqueous media remain inside the polymeric micelles due to their repulsive interactions with 
water. As nonrigid and dynamic systems, all the components can participate in the electrodeposition process. To analyze all of the individual and collective effects of each component in the electrochemical bath, the solutions summarized in Table 1 were prepared following the three-step procedure used for the preparation of the electrochemical bath used for the electrodeposition of Ni-rich Ni-Pt mesoporous films (i.e., the Ni-Pt solution in Table 1): First, $20 \mathrm{mg}$ of PS- $b$-PEO was dissolved in $6 \mathrm{~mL}$ of THF at $50{ }^{\circ} \mathrm{C}$. Second, once dissolved, $3 \mathrm{~mL}$ of ethanol and $2 \mathrm{~mL}$ of $80 \mathrm{mM} \mathrm{Ni}(\mathrm{OAc})_{2}+5 \mathrm{mM} \mathrm{Na}_{2} \mathrm{PtCl}_{6}$ aqueous solution were consecutively added under magnetic stirring (450 rpm). Third, $5 \mathrm{~mL}$ of $0.5 \mathrm{M} \mathrm{H}_{2} \mathrm{SO}_{4}$ solution was slowly added to the solution that was maintained under magnetic stirring at $450 \mathrm{rpm}$ at room temperature for $5 \mathrm{~h}$.

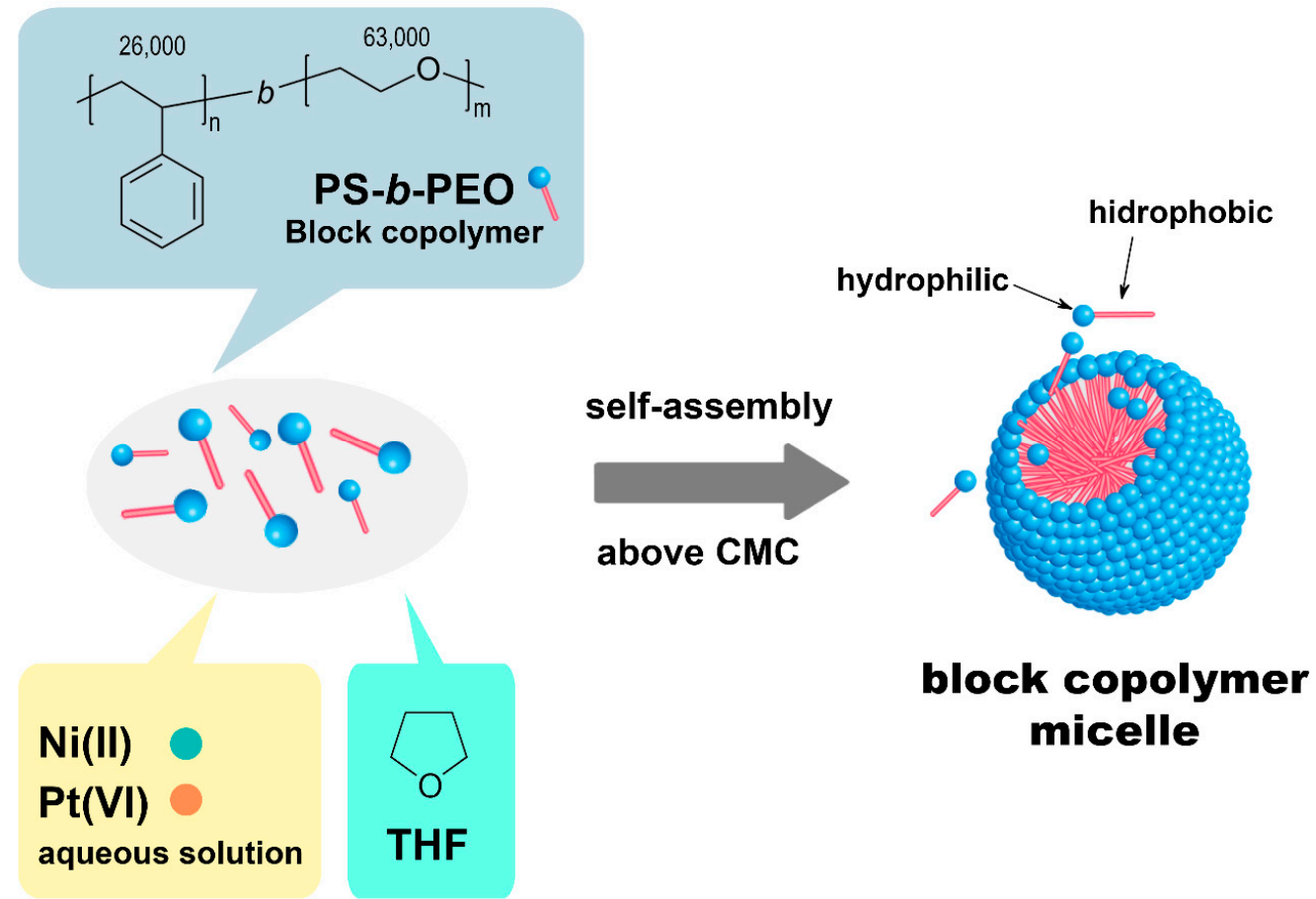

Scheme 1. Illustration of block copolymer micelles formation.

Table 1. Electrochemical baths and bath composition.

\begin{tabular}{|c|c|c|}
\hline Bath & Solution & Bath Composition \\
\hline 1 & THF solution & $6 \mathrm{~mL}$ of THF $+3 \mathrm{~mL}$ of ethanol $+2 \mathrm{~mL} \mathrm{H}_{2} \mathrm{O}+5 \mathrm{~mL}$ of $0.5 \mathrm{M} \mathrm{H}_{2} \mathrm{SO}_{4}$ \\
\hline 2 & PS- $b$-PEO solution & $\begin{array}{l}6 \mathrm{~mL} \text { of THF containing } 20 \mathrm{mg} \text { of PS- } b \text {-PEO }+3 \mathrm{~mL} \text { of ethanol }+ \\
22 \mathrm{~mL} \mathrm{H}_{2} \mathrm{O}+5 \mathrm{~mL} \text { of } 0.5 \mathrm{M} \mathrm{H}_{2} \mathrm{SO}_{4}\end{array}$ \\
\hline 3 & Ni solution & $\begin{array}{l}6 \mathrm{~mL} \text { of THF containing } 20 \mathrm{mg} \text { of PS- } b \text {-PEO }+3 \mathrm{~mL} \text { of ethanol }+ \\
2 \mathrm{~mL} \text { of } 80 \mathrm{mM} \mathrm{Ni}(\mathrm{OAc})_{2} \text { aqueous solution }+5 \mathrm{~mL} \text { of } 0.5 \mathrm{M} \mathrm{H}_{2} \mathrm{SO}_{4}\end{array}$ \\
\hline 4 & Ni-Pt solution & 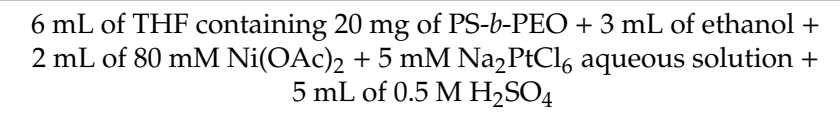 \\
\hline
\end{tabular}

\subsection{Electrochemical Characterization}

The electrochemical characterization of the systems was performed in a three-electrode cell with a potentiostat-galvanostat (Autolab PGSTAT30, Metrohm Autolab BV, Utrecht, Netherlands) equipped with GPES software (version 4.9). The working electrodes used were fluorine-doped tin oxide (FTO) and $\mathrm{Si} / \mathrm{Ti}(15 \mathrm{~nm}) / \mathrm{Au}(100 \mathrm{~nm})$ referred to hereafter as $\mathrm{Si} / \mathrm{Ti} / \mathrm{Au}$, with a geometrical area of $0.2 \mathrm{~cm}^{2}$ $(1 \times 0.2 \mathrm{~cm}$ for FTO and $0.5 \times 0.4 \mathrm{~cm}$ for Si/Ti/Au). Prior to use, the working electrodes were washed with absolute ethanol, rinsed with MilliQ water, and dried with nitrogen gas. A platinum spiral cleaned with flame annealing was used as the counter-electrode. For a reference electrode, an electrode 
of $\mathrm{Ag}|\mathrm{AgCl}| \mathrm{KCl}(3 \mathrm{M}) \mid \mathrm{SO}_{4}{ }^{2-}(0.5 \mathrm{M})$ was used. The potential limits were set at -1.5 and $0.4 \mathrm{~V}$ (vs. $\mathrm{Ag} \mid \mathrm{AgCl})$. All measurements were performed at $25 \pm 0.1^{\circ} \mathrm{C}$ under stationary conditions.

\subsection{Electrodeposition and Characterization of Ni-Rich Ni-Pt Mesoporous Films}

The $\mathrm{Ni}$ and Pt were codeposited using Ni-Pt solution by applying different potentials (i.e., -1.2 and $-1.3 \mathrm{~V}$ vs. $\mathrm{Ag} \mid \mathrm{AgCl})$ at $25 \pm 0.1^{\circ} \mathrm{C}$ under stationary conditions until attaining a fixed charge density of $7.5 \mathrm{C} \mathrm{cm}^{-2}$. Because the chief objective of the study was the electrodeposition of Ni-rich $\mathrm{Ni}$-Pt mesoporous films, potentials were selected, according voltammetric results, in order to ensure high Ni content. After electrodeposition, the Ni-Pt mesoporous films were washed with THF at $40 \pm 0.1^{\circ} \mathrm{C}$ for $30 \mathrm{~s}$ and rinsed with MilliQ water in order to remove deposited polymers. To study the influence of each of the system's components in the overall deposition process, parallel electrochemical characterization was also performed using the THF, the PS-b-PEO, and the Ni baths (Baths 1, 2, and 3, respectively).

Deposits were morphologically, architecturally, and elementally characterized by using field-emission scanning electron microscopy (FE-SEM) with Jeol JSM $7100 \mathrm{~F}$ (Tokyo, Japan) and Hitachi S-4800 (Ibaraki, Japan), both of which were equipped with an energy-dispersive X-ray spectroscopy detector. All of the samples were characterized before and after being cleaned with $100 \mathrm{~W}$ of $\mathrm{O}_{2}$ plasma for $45 \mathrm{~min}$. The thickness of deposits was determined by using a 3D optical surface metrology system (Leica DCM 3D, Wetzlar, Germany). The elemental composition was also examined by using X-ray fluorescence (XRF) spectrometry with a Fischerscope X-ray XDV-SDD (Fischer Instruments, Barcelona, Spain). In some samples, X-ray photoelectron spectroscopy (XPS) was also used to verify the deposition of metal. XPS data were acquired using the PHI ESCA-5500 Multitechnique system (Physical Electronics, Feldkirchen, Germany) at a base pressure of $5 \times 10^{-10}$ mbar using monochromatic $\mathrm{Al} \mathrm{K}$-alpha radiation (i.e., $\mathrm{Al} \mathrm{K} \alpha$ line of $1486.6 \mathrm{eV}$ energy and $350 \mathrm{~W}$ ) as the excitation source. The Brunauer-Emmett-Teller (BET) surface areas were measured from $\mathrm{N}_{2}$ adsorption-desorption isotherms at $77 \mathrm{~K}$ using a Micrometrics Tristar-II (Micrometrics, Ottawa, ON, Canada). The crystal phases were determined by X-ray diffraction (XRD) with a Bruker D8 Discovery diffractometer (Billerica, MA, USA) in the Bragg-Brentano configuration with $\mathrm{Cu} \mathrm{K}_{\alpha}$ radiation.

\subsection{Electrocatalytic Performance}

The electrocatalytic performance of the prepared mesoporous films for methanol electro-oxidation was evaluated in alkaline conditions $(\mathrm{KOH} 1 \mathrm{M})$. The measurements were taken in a three-electrode cell using a potentiostat-galvanostat (Autolab PGSTAT30, Metrohm Autolab BV, Utrecht, Netherlands) equipped with Nova software (version 2.1). Mesoporous films, $\mathrm{Pt}$ spirals, and $\mathrm{Ag}|\mathrm{AgCl}| \mathrm{KCl}(3 \mathrm{M}) \mid \mathrm{SO}_{4}{ }^{2-}$ $(0.5 \mathrm{M})$ were used as working, counter, and reference electrodes, respectively. The working electrode was previously subjected to 40 cyclic voltammograms between -1.5 and $0.4 \mathrm{~V}$ at $10 \mathrm{mV} \mathrm{s}^{-1}$ for conditioning in a $\mathrm{KOH}$ solution of $1 \mathrm{M}$ at $25 \pm 0.1^{\circ} \mathrm{C}$. The methanol oxidation reaction (MOR) was studied in solutions of $1 \mathrm{M}$ methanol in $1 \mathrm{M} \mathrm{KOH}$ solution using the same potential window and a scan rate of $50 \mathrm{mV} \mathrm{s}^{-1}$. The stability and durability of the prepared mesoporous films were examined by measuring the catalytic performance after 1000 cycles in $1 \mathrm{M}$ methanol $+1 \mathrm{M}$ of $\mathrm{KOH}$ solution using the same potential window and a scan rate of $100 \mathrm{mV} \mathrm{s}^{-1}$.

\section{Results}

A systematic study of the various components of the system was performed in order to identify the limitations and robustness of using block copolymer-templated electrodeposition to electrosynthesize mesoporous materials. The effects of two typical electrodes (i.e., FTO-coated glass and $\mathrm{Si} / \mathrm{Ti} / \mathrm{Au}$ electrodes) ideal for use in a wide range of applications, including optoelectronics, thin-film photovoltaics, energy-saving windows, and catalysis, were also examined. 


\subsection{Electrochemical Characterization}

To study the electrochemical behavior of block copolymer-templated electrodeposition, voltammetric studies on the $\mathrm{FTO}$ and $\mathrm{Si} / \mathrm{Ti} / \mathrm{Au}$ substrates were performed in four different electrochemical baths (Table 1), all at a controlled temperature of $25^{\circ} \mathrm{C}$ and in stationary conditions. As shown in Figure 1a, using FTO, similar electrochemical behavior was observed in the THF (i.e., Bath 1), PS-b-PEO (i.e., Bath 2), and Ni (i.e., Bath 3) solutions, all of which demonstrated a clear reduction current (R1) on the cathodic scan at approximately $-0.8 \mathrm{~V}$ (vs. $\mathrm{Ag} \mid \mathrm{AgCl}$ ). Although analogous general behavior was observed with the Si/Ti/Au electrodes (Figure 1b), the reduction peaks in the PS- $b$-PEO (Bath 2) and Ni solutions (Bath 3) began at slightly more negative potentials of around $-0.65 \mathrm{~V}$ (vs. $\mathrm{Ag} \mid \mathrm{AgCl}$ ) than with the THF solution (Bath 1), which began peaking at approximately $-0.5 \mathrm{~V}$ (vs. $\mathrm{Ag} \mid \mathrm{AgCl})$. As easily observable on the slope of the reduction peak, the reduction in the THF solution (Bath 1) occurred at a higher rate, especially in the case of FTO. That outcome suggests that THF participated in the reduction process as the formation of polymeric micelles (i.e., PS- $b$-PEO and Ni solutions), which partially blocked THF's interaction with the electrode's surface and significantly reduced the kinetics of electroreduction. In a previous study, when Ni solution was studied on $\mathrm{Si} / \mathrm{Ti} / \mathrm{Au}$, the reduction peak at approximately $-0.8 \mathrm{~V}$ (vs. $\mathrm{Ag} \mid \mathrm{AgCl}$ ) was assigned to the simultaneous $\mathrm{Ni}$ (II) reduction to metallic $\mathrm{Ni}$ and the hydrogen evolution reaction [37]. Note that the cyclic voltammogram profiles in the presence and in the absence of $\mathrm{Ni}$ (II) in both PS- $b$-PEO and Ni solutions were identical.

a

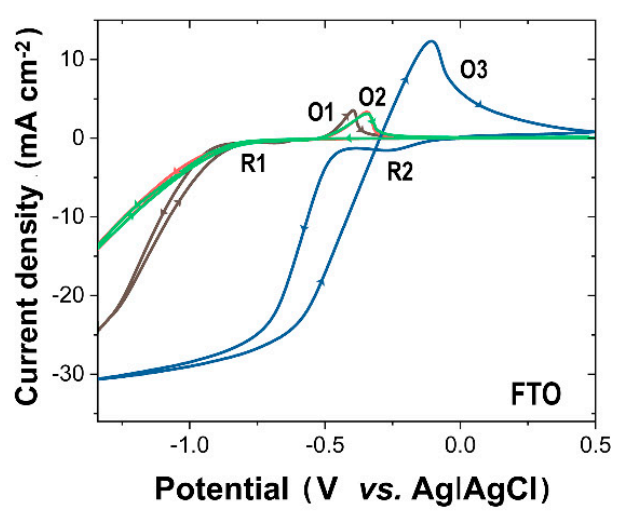

- THF - PS-b-PEO b

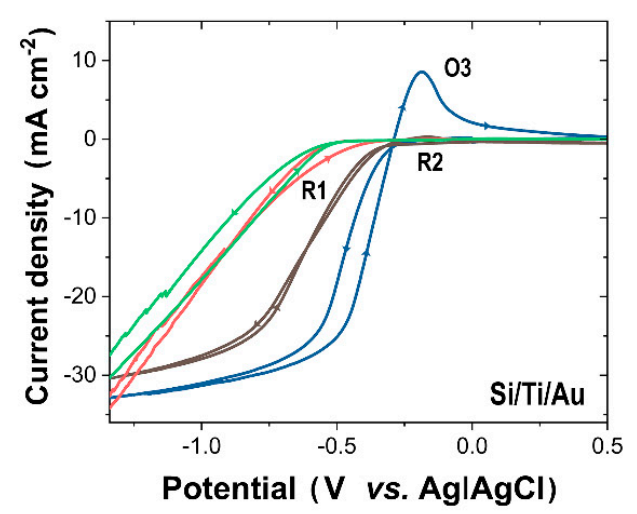

$\longrightarrow \mathrm{Ni} \quad-\mathrm{Ni}-\mathrm{Pt}$

Figure 1. Cyclic voltammograms of the four electrochemical baths (i.e., THF (black), PS- $b$-PEO (red), $\mathrm{Ni}$ (green), and Ni-Pt (blue)) on (a) FTO-coated glass and (b) Si/Ti/Au at $50 \mathrm{mV} \mathrm{s}^{-1}$ and $25^{\circ} \mathrm{C}$.

By contrast, the anodic scan on FTO revealed a clear oxidation peak (O1) at approximately $-0.55 \mathrm{~V}$ (vs. $\mathrm{Ag} \mid \mathrm{AgCl}$ ) in the THF solution and another $(\mathrm{O} 2)$ at approximately $-0.60 \mathrm{~V}$ (vs. $\mathrm{Ag} \mid \mathrm{AgCl})$ in the PS- $b$-PEO and Ni solutions. All of those oxidation peaks rose significantly in the oxidation scan after the potential was maintained at $-1.3 \mathrm{~V}$ (vs. $\mathrm{Ag} \mid \mathrm{AgCl}$ ) during $60 \mathrm{~s}$ in the negative scan under the same conditions. A thin layer could be observed on the FTO electrodes after $60 \mathrm{~s}$ of deposition at $-1.3 \mathrm{~V}$. However, no oxidation peaks — that is, neither $\mathrm{O} 1$ nor $\mathrm{O} 2$ - were recorded when $\mathrm{Si} / \mathrm{Ti} / \mathrm{Au}$ was used as a working electrode. It is well known that FTO catalyzes the electrodeposition of various polymers such as polypyrrole, polyaniline, poly(3,4-ethylenedioxythiophene), and polybithiophene [39-41]. Consequently, the reduction peak observed with the THF (Bath 1), PS- $b$-PEO (Bath 2), and Ni (Bath 3) solutions can be assumed to indicate the simultaneous deposition of THF, PS- $b$-PEO, and/or Ni, depending on the system, as well as the hydrogen evolution reaction. Therefore, the oxidation peak $\mathrm{O} 1$ could be assigned to the polytetrahydrofuran's electro-oxidation, whereas $\mathrm{O} 2$ could be ascribed to the partial oxidation of the deposited block copolymer. The codeposition of polymers could benefit the formation of decorated or even mesoporous architectures. Previous studies have demonstrated the 
codeposition of metals and spherical polymeric micelles present in the electrolyte, which prompted the formation of mesoporous metallic structures following the dissolution of the polymers [42-44]. After all, the surface charge of polymeric micelles is a key factor for attraction to the working electrode's surface, as well as for the selection of the system's constituents. In that way, well-defined metallic mesoporous materials are deposited, because the global surface charge of the polymeric micelles should be positive to be electrostatically attracted to the negatively polarized surface of the working electrode.

However, different voltammetric behavior was observed in the presence of the $\left[\mathrm{PtCl}_{6}\right]^{2-}$ complex (Bath 4), as evidenced by the advance of the reduction peak's $\left(\mathrm{R}_{2}\right)$ onset to approximately $-0.5 \mathrm{~V}$ (vs. $\mathrm{Ag} \mid \mathrm{AgCl}$ ) on $\mathrm{FTO}$ and $-0.4 \mathrm{~V}$ (vs. $\mathrm{Ag} \mid \mathrm{AgCl}$ ) on $\mathrm{Si} / \mathrm{Ti} / \mathrm{Au}$, under the influence of the interaction of $\left[\mathrm{PtCl}_{6}\right]^{2-}$ anions in the hydrophilic part of the polymeric micelles. The intensity of the subsequent reduction peak also increased due to the promotion of the hydrogen evolution reaction on the previously deposited Ni-Pt. In the anodic scan, a clear oxidation peak (O3) at approximately $-0.30 \mathrm{~V}(\mathrm{vs} . \mathrm{Ag} \mid \mathrm{AgCl})$ was observed, which was ascribed to the Ni-Pt's oxidation. Such behavior suggests that the interaction between the Pt complex and the hydrophilic part of the polymeric micelles promoted the codeposition of $\mathrm{Pt}$ and the copolymer; the freshly deposited metal unambiguously promoted the codeposition of $\mathrm{Ni}$, and enhanced the hydrogen evolution reaction.

\subsection{Analysis of the Potential Interference of Organic Component and Block Copolymer Micelles on the Deposition of Ni-Rich Ni-Pt Mesoporous Films}

Based on the cyclic voltammetric study, Ni-rich Ni-Pt mesoporous films were potentiostatically electrodeposited at -1.3 and $-1.2 \mathrm{~V}$ (vs. $\mathrm{Ag} \mid \mathrm{AgCl}$ ) in the $\mathrm{Ni}-\mathrm{Pt}$ (Bath 4) solution under stationary conditions until the same deposition charge density $\left(7.5 \mathrm{C} \mathrm{cm}^{-2}\right)$ was attained. To analyze the potential interference of each component of the block copolymer micellar system, electrodeposition in the same conditions at $-1.3 \mathrm{~V}$ (vs. Ag|AgCl) was also performed using the THF (Bath 1) and PS- $b$-PEO (Bath 2) solutions. After electrodeposition, all of the samples were cleaned with pure THF at $40{ }^{\circ} \mathrm{C}$ in order to remove the remaining block copolymer. Next, the samples were subjected to $100 \mathrm{~W}$ of $\mathrm{O}_{2}$ plasma for $45 \mathrm{~min}$ to remove the deposited organic matter. Among the results, the first difference observed was that, to the naked eye, the samples prepared on $\mathrm{Si} / \mathrm{Ti} / \mathrm{Au}$ did not reveal the presence of any deposit, whereas a gray, metal-like coating was observed on FTO in all cases.

From the THF solution, a homogeneous tridimensional mesoporous architecture (Figure 2a) was also obtained on the FTO-coated glass, whereas no deposit was observed on Si/Ti/Au (Figure 2b). As the results of the preliminary electrochemical study suggested would occur, the electrodeposition of the polytetrahydrofuran was catalyzed by FTO-coated glass only. By contrast, the electrodeposits obtained using the PS- $b$-PEO solution revealed the formation of a fluffy film on FTO (Figure 3a) and compact films with spherical grains on $\mathrm{Si} / \mathrm{Ti} / \mathrm{Au}$ (Figure $3 \mathrm{~b}$ ), both due to the electropolymerization of the block copolymer. The morphological analysis of those samples was performed prior to cleaning the deposit with THF and $\mathrm{O}_{2}$ plasma in order to check the true morphology of the deposits. Both polymeric films were greatly affected and entirely removed when subjected to $\mathrm{O}_{2}$ plasma for a prolonged period (>120 min).

The electropolymerization of both THF and block copolymer must always be considered when a block copolymer-templated electrodeposition is used for the synthesis of mesoporous materials. As block copolymer micelles are dynamic systems, it is expected that both THF and the block copolymer also interacted with the working electrode surface during electrodeposition, and consequently, codeposited simultaneously with other electroactive species like $\mathrm{Ni}(\mathrm{II})$ or $\mathrm{Pt}(\mathrm{VI})$. This process can be beneficial for the creation of pores, if polymers are etched or dissolved, but can also reduce mesopores definition or even film integrity. 

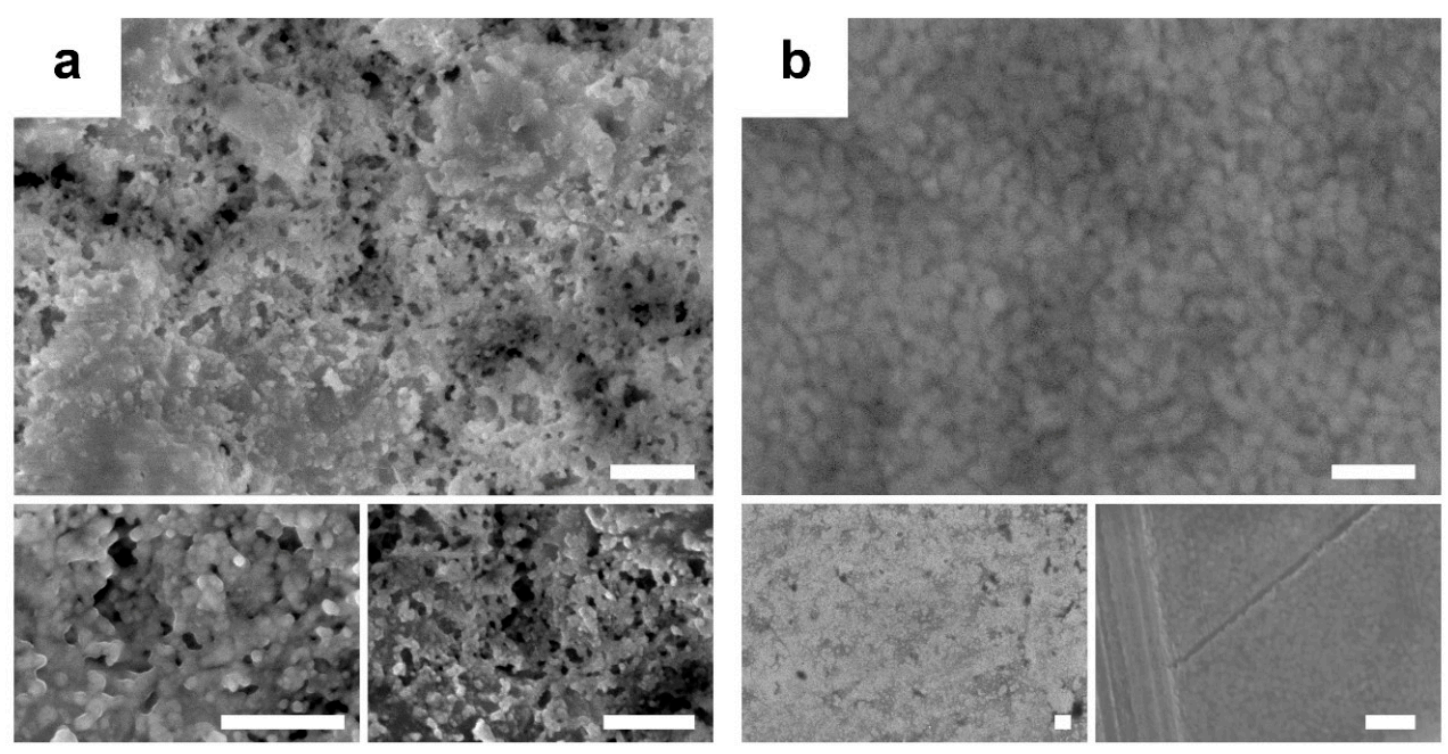

Figure 2. FE-SEM micrographs at different magnifications of the deposits obtained using the THF (Bath 1) solution on (a) FTO-coated glass and (b) $\mathrm{Si} / \mathrm{Ti} / \mathrm{Au}$ substrates at $-1.3 \mathrm{~V}$ (vs. $\mathrm{Ag} \mid \mathrm{AgCl}$ ) after circulating $7.5 \mathrm{C} \mathrm{cm}^{-2}$. Scale bar: $300 \mathrm{~nm}$.
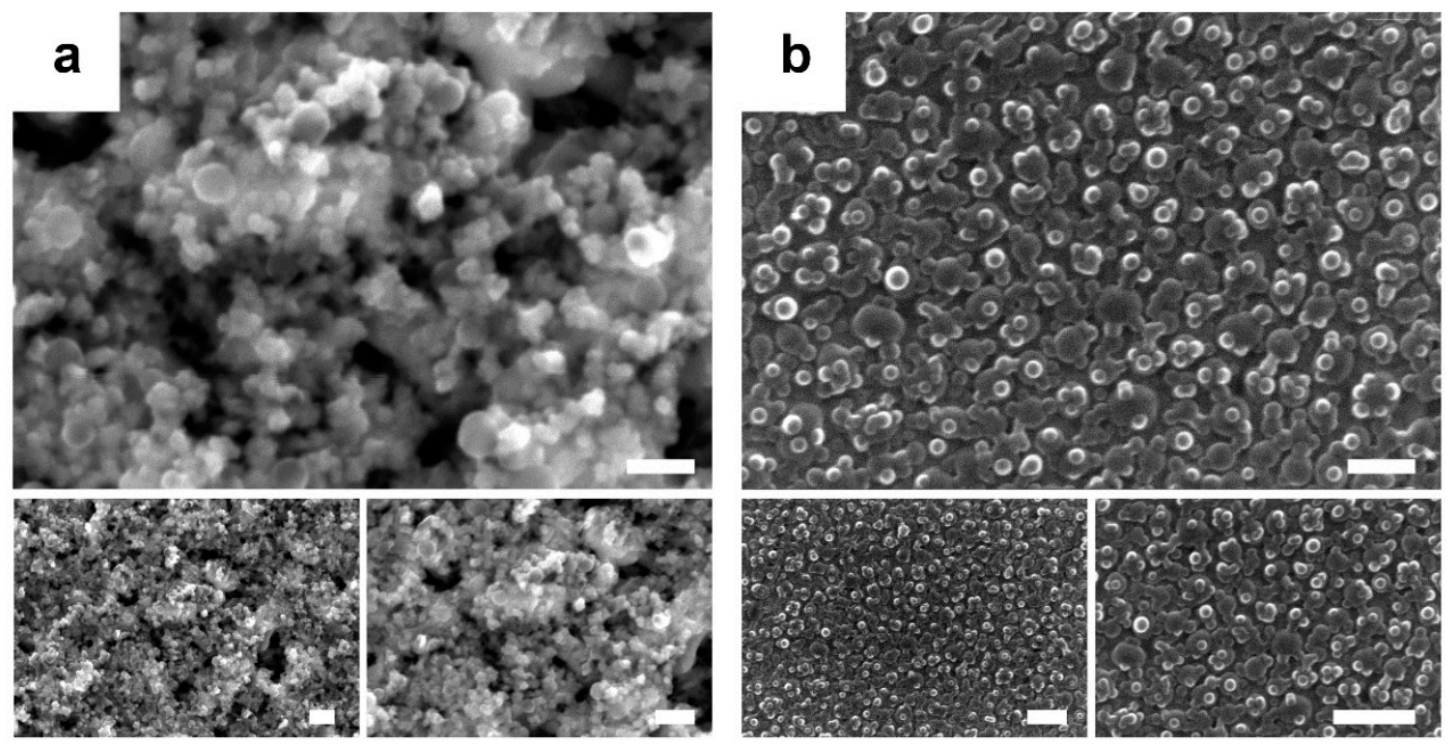

Figure 3. FE-SEM micrographs at different magnifications of the deposits obtained using PS- $b$-PEO (Bath 2) solution on (a) FTO-coated glass and (b) Si/Ti/Au substrates at $-1.3 \mathrm{~V}$ (vs. Ag|AgCl) after circulating $7.5 \mathrm{C} \mathrm{cm}^{-2}$. Scale bar: $300 \mathrm{~nm}$.

\subsection{Electrodeposition and Characterization of Ni-Rich Ni-Pt Mesoporous Films}

With the aim to reduce the use of expensive noble metals in electrodeposition, as well as to analyze the potential of block copolymer-templated electrodeposition for materials not based on $\mathrm{Pt}$ or $\mathrm{Au}$, electrodeposition was performed in the $\mathrm{Ni}$ (Bath 3) solution. The deposits obtained from that solution (Figure 4a) on FTO presented a 3D sponge network morphology, with pores ranging from approximately 80 to $200 \mathrm{~nm}$, which highlights the extremely relevant role of the ionic salt used in the deposition.

When the $\mathrm{Ni}(\mathrm{OAc})_{2}$ precursor was used in acidic conditions, the electrostatic repulsion of positively charged $\mathrm{Ni}(\mathrm{II})$ ions with the positively charged polymeric micelles inhibited their interaction. However, minimal adsorption of positively charged $\mathrm{Ni}$ (II) ions via hydrogen bonding was expected [37]. 
The primary $\mathrm{Ni}(\mathrm{II})$ species in the aqueous solution in those conditions was $\mathrm{Ni}^{2+}$ ions. Because the non-nickel functionalized positively charged polymeric micelles were attracted to the working electrode, the definition of mesopores was poor, and the effect of THF's deposition was more important. After all, polymeric micelles are dynamic systems and THF is not entirely physically retained in the inner part of the polymeric micelles. The elemental analysis of those deposits confirmed the global codeposition of $\mathrm{Ni}$; however, Ni was not locally detected even in the XPS analysis of various regions of the deposits (Figure S1, Supplementary Material). Because the deposit was partially removed when subjected to an $\mathrm{O}_{2}$ plasma treatment (Figure S2, Supplementary Material), Ni-decorated microporous films could be easily obtained using block copolymer-templated electrodeposition in those conditions.

The electrodeposition on Si/Ti/Au, in which the electropolymerization of THF was not catalyzed, facilitated the codeposition of $\mathrm{Ni}$ and the block copolymer, thereby prompting the formation of mesoporous Ni films (Figure 4b). However, the efficiency of electrodeposition was extremely low, and deposits were heterogeneously distributed in the corners of the working electrode. In those samples, three regions could be easily distinguished. The first was the Si/Ti/Au surface without any deposit, which encompassed most of the surface. The second region contained compact films of copolymer (Figure S3, Supplementary Material) that were identical to those obtained with the PS-b-PEO solution (Figure $3 b$ ), which can be attributed to the deposition of polymeric micelles that did not contain adsorbed $\mathrm{Ni}^{2+}$ ions. The last region consisted of mesoporous $\mathrm{Ni}$ films at the corners of the working electrode (Figure $4 \mathrm{~b}$ ). Due to the heterogeneity of the deposits, the measured average thickness ranging from $<100$ to $>600 \mathrm{~nm}$ clearly observed for the samples has not been reported. Therefore, using block copolymer-templated electrodeposition to prepare continuous mesoporous Ni needs to be improved, particularly using other $\mathrm{Ni}$ precursors that can electrostatically interact with the hydrophilic part of polymeric micelles, whose surface charge was positive, which promoted access to the electrode and overcame the intrinsically inert character of Ni during electrodeposition.
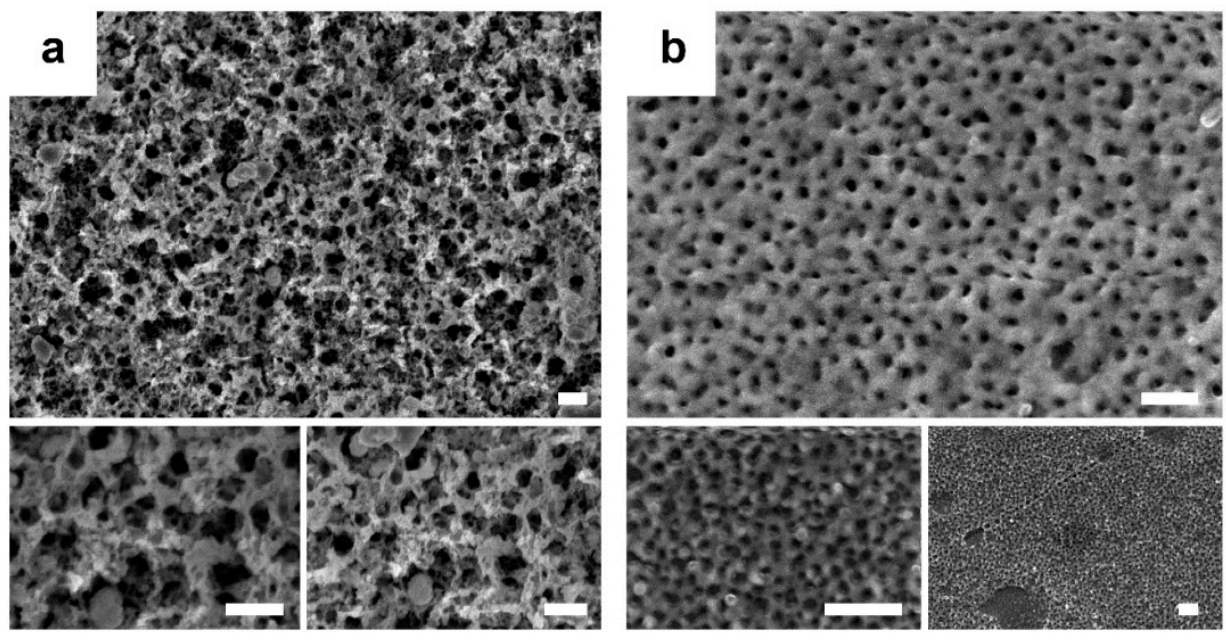

Figure 4. FE-SEM micrographs at different magnifications of the deposits obtained using Ni (Bath 3) solution on (a) FTO-coated glass and (b) $\mathrm{Si} / \mathrm{Ti} / \mathrm{Au}$ substrates at $-1.3 \mathrm{~V}$ (vs. Ag|AgCl) after circulating $7.5 \mathrm{C} \mathrm{cm}^{-2}$. Scale bar: $300 \mathrm{~nm}$.

Last, using the Ni-Pt (Bath 4) solution, in which the negatively charged platinum (IV) chloro complexes were the primary platinum species (i.e., in the working conditions), mesoporous films of Ni-rich Ni-Pt were electrosynthesized. The coexisting platinum (IV) chloro complexes in aqueous solution interacted electrostatically with the hydrophilic part of the polymeric micelles, thereby rendering the global surface charge of Pt-functionalized micelles positive, even in the presence of $\mathrm{Ni}(\mathrm{II})$, and thus, favoring the attraction of polymeric micelles on the negatively polarized surface of the working electrode. In that dynamic, the polymeric micelles functioned as the porogen agent used in block copolymer-templated electrodeposition. As shown in Figure 5a,b, 3D mesoporous films, with 
pore diameters ranging from approximately 30 to $35 \mathrm{~nm}$, were electrodeposited over the entire surface of FTO and Si/Ti/Au electrodes. Consequently, selecting an appropriate metallic precursor is pivotal to guarantee definition of mesopores in block copolymer-templated electrodeposition.
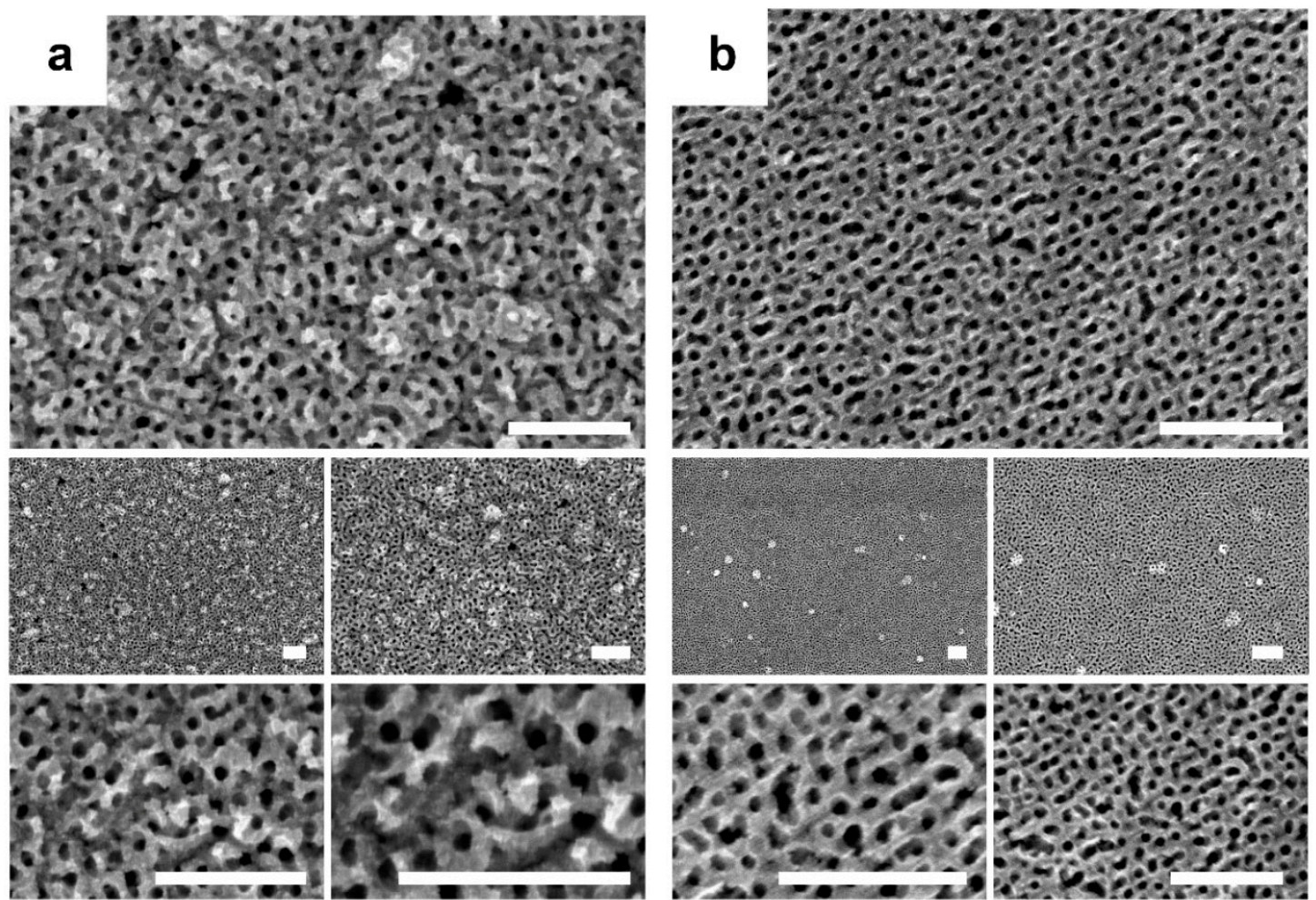

Figure 5. FE-SEM micrographs at different magnifications of the deposits obtained using Ni-Pt (Bath 4) solution on (a) FTO-coated glass and (b) Si/Ti/Au substrates at $-1.3 \mathrm{~V}$ (vs. Ag|AgCl) after circulating $7.5 \mathrm{C} \mathrm{cm}^{-2}$. Scale bar: $300 \mathrm{~nm}$.

By changing the electrodeposition potential, the Ni/Pt ratio could be modified in the synthesized mesoporous films. When most negative deposition potentials were applied, the Ni content in the films was higher. By contrast, a decrease in the porosity of the films was also observed when $\mathrm{Ni}$ content increased. This dynamic confirms the relevance of the $\left[\mathrm{PtCl}_{6}\right]^{2-}$ complex to the system as the species that interacts with the hydrophilic part of the polymeric micelles and, in that role, prompts the deposition of well-defined, uniformly distributed Ni-rich Ni-Pt mesoporous films. Indeed, the described interaction is the determining factor in the production of mesoporous films, because compact deposits would be obtained otherwise. Therefore, a compromise between Ni content and the integrity of mesopores was required to obtain films exhibiting a mesoporous structure with the most Ni content. In those conditions, in terms of $\mathrm{Ni}$ content and the definition of porosity, the most adequate conditions occurred with potentiostatic electrodeposition at -1.2 (Figure S4, Supplementary Material) and $-1.3 \mathrm{~V}$ (Figure 5), both versus $\mathrm{Ag} \mid \mathrm{AgCl}$, in which the mesopores were uniformly distributed over the entire surface without any visible voids or cracks. After the total removal of organic matter by $\mathrm{O}_{2}$ plasma treatment, the composition of the Ni-rich Ni-Pt mesoporous films (Table 2) was subjected to EDX and $\mathrm{XRF}$ analysis. According to the literature, $\mathrm{Ni}$ content can be enhanced by increasing the temperature during electrodeposition and, in turn, accelerating the transport of $\mathrm{Ni}$ (II) ions from the electrolyte to the working electrode. Based on such evidence, the reduction in $\mathrm{Ni}^{2+} / \mathrm{Ni}$ can hardly occur at temperatures below $40{ }^{\circ} \mathrm{C}$. However, in the experiment described here, the Ni-rich Ni-Pt mesoporous films were successfully electrodeposited at $25^{\circ} \mathrm{C}$. 
Table 2. Deposition potential, average thickness, elemental composition, pore diameter, and BET surface area of the Ni-rich $\mathrm{Ni}-\mathrm{Pt}$ mesoporous films.

\begin{tabular}{ccccccccc}
\hline $\begin{array}{c}\text { Deposition } \\
\text { Potential (V vs. } \\
\text { Ag|AgCl) }\end{array}$ & \multicolumn{2}{c}{ Thickness (nm) } & \multicolumn{2}{c}{$\begin{array}{c}\text { Elemental Composition } \\
\text { (at. \%) }\end{array}$} & Pore Diameter (nm) & $\begin{array}{c}\text { BET Surface Area } \\
\left(\mathbf{m}^{\mathbf{2}} \mathbf{g}^{-\mathbf{1}}\right)\end{array}$ \\
\cline { 2 - 9 } & FTO & Si/Ti/Au & FTO & Si/Ti/Au & FTO & Si/Ti/Au & FTO & Si/Ti/Au \\
\hline-1.2 & $\sim 540$ & $\sim 490$ & $66 \pm 2 \%$ of Ni & $64 \pm 1 \%$ of Ni & $20-30$ & $20-30$ & - & - \\
-1.3 & $\sim 520$ & $\sim 480$ & $74 \pm 1 \%$ of $\mathrm{Ni}$ & $71 \pm 2 \%$ of $\mathrm{Ni}$ & $20-35$ & $25-35$ & 66 & 62 \\
\hline
\end{tabular}

The Ni-rich Ni-Pt mesoporous films prepared at $-1.3 \mathrm{~V}$ (vs. $\mathrm{Ag} \mid \mathrm{AgCl}$ ) were subjected to nitrogen gas adsorption and desorption in order to determine the BET surface areas. As shown in Figure $6 a, b$, a gradual increase in adsorbed nitrogen up to relative pressure of approximately 0.75 was observed, followed by a hysteresis loop between relative pressure values of 0.75 to 0.995 , which suggests the mesoporous nature of both films. The Ni-rich Ni-Pt mesoporous films prepared on FTO exhibited a BET surface area of $66 \mathrm{~m}^{2} \mathrm{~g}^{-1}$ and an average pore diameter of $26 \mathrm{~nm}$, whereas the ones prepared on $\mathrm{Si} / \mathrm{Ti} / \mathrm{Au}$ exhibited a BET surface area of $62 \mathrm{~m}^{2} \mathrm{~g}^{-1}$ and an average pore diameter of $25 \mathrm{~nm}$. The average pore diameters agreed well with results obtained earlier from FE-SEM analysis. Therefore, the prepared Ni-rich Ni-Pt mesoporous films should be excellent candidates with high-performance electrocatalytic activity for MOR due to the enhanced surface area.

a

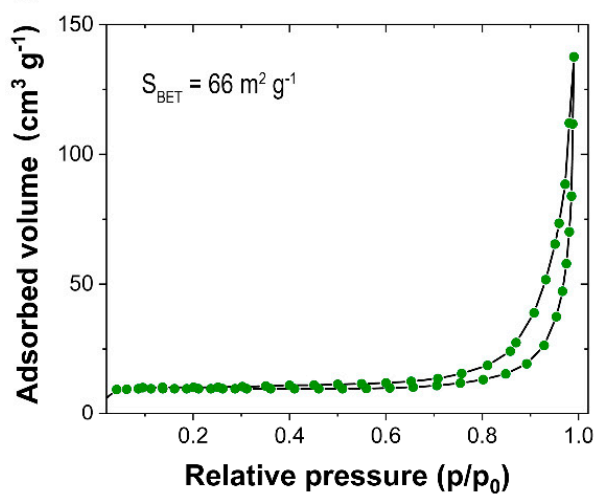

C

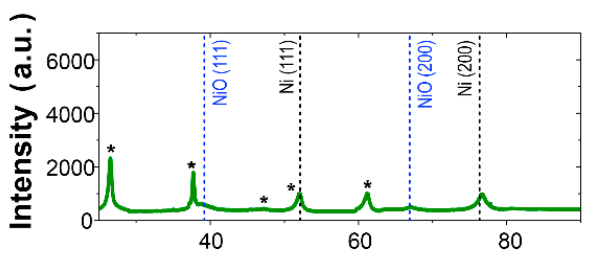

$2 \theta\left({ }^{\circ}\right)$ b

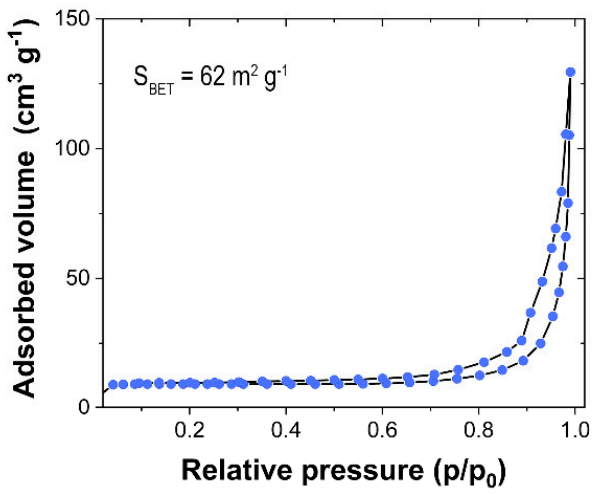

d

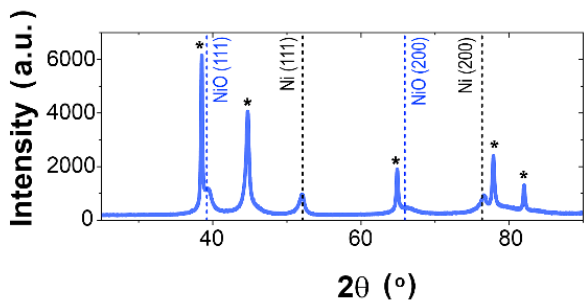

Figure 6. $(\mathbf{a}, \mathbf{b})$ Nitrogen adsorption and desorption isotherms and $(\mathbf{c}, \mathbf{d})$ XRD patterns of Ni-rich Ni-Pt mesoporous films prepared at $-1.3 \mathrm{~V}$ (vs. $\mathrm{Ag} \mid \mathrm{AgCl}$ ) on (a) $\mathrm{FTO}$ and (b) $\mathrm{Si} / \mathrm{Ti} / \mathrm{Au}$ substrates. The diffraction peaks that correspond to the FTO and $\mathrm{Si} / \mathrm{Ti} / \mathrm{Au}$ substrates, respectively, are indicated by *

The XRD patterns (Figure 6c,d) show the (111) and (200) reflections for Ni face-centered cubic $(f c c)$ crystal phase, along with the reflections of the FTO (Figure 6c) and Au (Figure 6d) seed layers. However, the (111) and (200) reflections for $\mathrm{NiO} f c c$ crystal phase were also detected, which was expected due to the superficial oxidation possible during the oxygen plasma treatment that removes the codeposited organic matter. The formation of $\mathrm{NiO}$ can also benefit MOR in alkaline conditions.

Consequently, well-defined bimetallic Ni-rich Ni-Pt alloyed mesoporous films, easily synthesized using block copolymer-templated electrodeposition, on FTO-coated glass and Si/Ti/Au electrodes, 
are expected to possess excellent electrocatalytic performance for MOR due to the large surface area and the synergetic effects of the architecture combined with the chemical and electronic properties.

\subsection{Electrocatalytic Performance}

The electrocatalytic properties of Ni-rich Ni-Pt mesoporous films for the methanol oxidation reaction (MOR) on FTO-coated glass and $\mathrm{Si} / \mathrm{Ti} / \mathrm{Au}$ substrates were compared to pure $\mathrm{Pt}$ mesoporous films at $1 \mathrm{M}$ of $\mathrm{KOH}$ containing $1 \mathrm{M}$ of methanol using cyclic voltammetry (CV), as shown in Figure 7 . Once the currents were normalized using the Pt mass of electrodeposits, the CV profiles revealed similar methanol oxidation peaks in the forward scan (Ox1) for FTO and Si/Ti/Au electrodes. Such peaks can be ascribed to the electro-oxidation of freshly chemisorbed methanol, whereas a significantly smaller oxidation peak in the backward scan (Ox2) can be ascribed to the removal and oxidation of residually adsorbed carbonaceous intermediates produced during the forward scan [45-47]. As expected, the mass activity (i.e., current normalized by Pt mass) and the surface activity (i.e., current normalized by BET surface area) of Ni-rich Ni-Pt mesoporous films were significantly (i.e., approximately 5 times) and slightly (i.e., approximately 1.2 times) higher, respectively, than the activities observed for $\mathrm{Pt}$ mesoporous films (i.e., independently on the substrate) due to the significantly lower amount of $\mathrm{Pt}$ in $\mathrm{Ni}$-rich Ni-Pt mesoporous films for a virtually identical specific surface area. Both mass and surface activities were slightly higher on the FTO than on the Si/Ti/Au substrates, as consistent with their slightly higher BET surface areas. The MOR activity of Ni-rich Ni-Pt mesoporous films was comparable to, if not higher than, what has been reported in the literature for MORs in alkaline conditions with state of the art Pt-based catalysts (Table 3) [48-56]. The negative shift in the onset potential (E $E_{\text {onset }}$, Table 3 ) and peak potential ( $E_{p}$, Table 3 ) for both the FTO-coated glass and the Si/Ti/Au Ni-rich Ni-Pt mesoporous films indicated significant improvement in the kinetics of methanol electro-oxidation compared with that of pure Pt structures under the same experimental conditions, possibly due to the synergistic effect of mesoporous morphology and chemical composition. In addition, a third oxidation voltammetric peak (Ox3) was observed that could be attributed to the superficial oxidation of $\mathrm{Ni}-\mathrm{Pt}$ mesoporous films, with a peak that was also detected in the absence of methanol, from the solution (i.e., $1 \mathrm{M}$ of $\mathrm{KOH}$ ). Ni-rich $\mathrm{Ni}-\mathrm{Pt}$ mesoporous films can oxidize methanol to carbon dioxide more efficiently than pure Pt or other electrocatalysts due to the former's higher tolerance to the intermediate carbonaceous species (e.g., $\mathrm{CO}_{\mathrm{ads}}$ and $\mathrm{CHO}_{\mathrm{ads}}$ ) accumulated on the surface of the electrodes. A major limitation of Pt electrocatalysts in MORs, however, is the low tolerance of $\mathrm{Pt}$ to $\mathrm{CO}_{\text {ads }}$ poisoning, which can be easily evaluated by using the ratio of the forward anodic peak's current density $\left(j_{f}\right)$ to that of the backward anodic peak $\left(j_{b}\right)$. As shown in Table 3 , higher $j_{f} / j_{b}$ ratios indicate a higher tolerance to poisoning. In the experiment, the tolerance of the Ni-rich Ni-Pt mesoporous films was significantly higher than the state of the art Pt-based catalysts [48-56].

The long-term stability and durability of electrocatalysts are important parameters in determining whether Ni-rich Ni-Pt mesoporous films are promising applicable electrocatalysts for fuel cells. The durability of electrocatalysts was, therefore, initially evaluated with cyclic voltammetry (i.e., 1000 cycles using the same potential window and a scan rate of $100 \mathrm{mV} \mathrm{s}^{-1}$ ) and chronoamperometry (i.e., at $-0.15 \mathrm{~V}$ vs. $\mathrm{Ag} \mid \mathrm{AgCl}$ for $7200 \mathrm{~s}$ ) in a solution containing $1 \mathrm{M}$ of $\mathrm{KOH}$ and $1 \mathrm{M}$ of methanol. As shown Figure $7 \mathrm{c}, \mathrm{d}$, the scanning peak currents before and after 1000 cycles exhibited an attenuation of $14.8 \%$ and $12.5 \%$ for Ni-rich Ni-Pt mesoporous films on FTO-coated glass and Si/Ti/Au substrates, respectively. Those values indicate an acceptable durability compared with the state of the art Pt-based electrocatalysts for methanol electro-oxidation in both acidic and alkaline conditions. The durability of Ni-rich Ni-Pt mesoporous films was additionally confirmed by chronoamperometry. As shown Figure $7 \mathrm{e}, \mathrm{f}$, the high steady-state current densities achieved after the initial decrease due to the generation of reactive intermediate species, which aligned with those obtained from $\mathrm{CV}$, also demonstrated excellent catalytic performance compared with the state of the art Pt-based electrocatalysts. The stability and durability of the catalyst were also morphologically and structurally confirmed by using FE-SEM observation and 
XRD analysis (Figure S5, Supplementary Material). After the 1000-cycle test experiments, no effects were observed on either the morphology or the structure of the deposits independent of the substrate used.

a

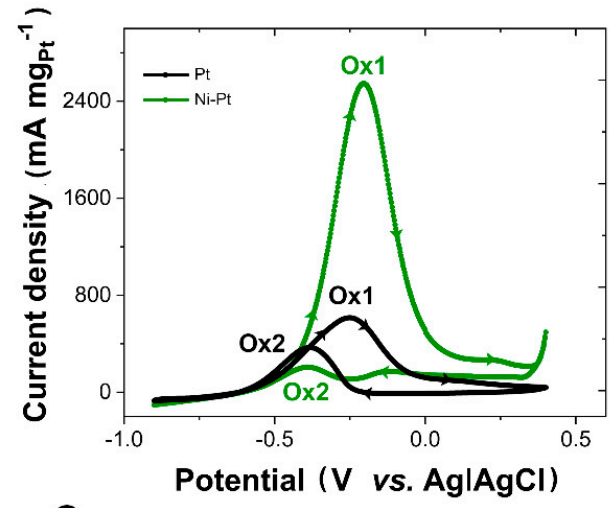

C
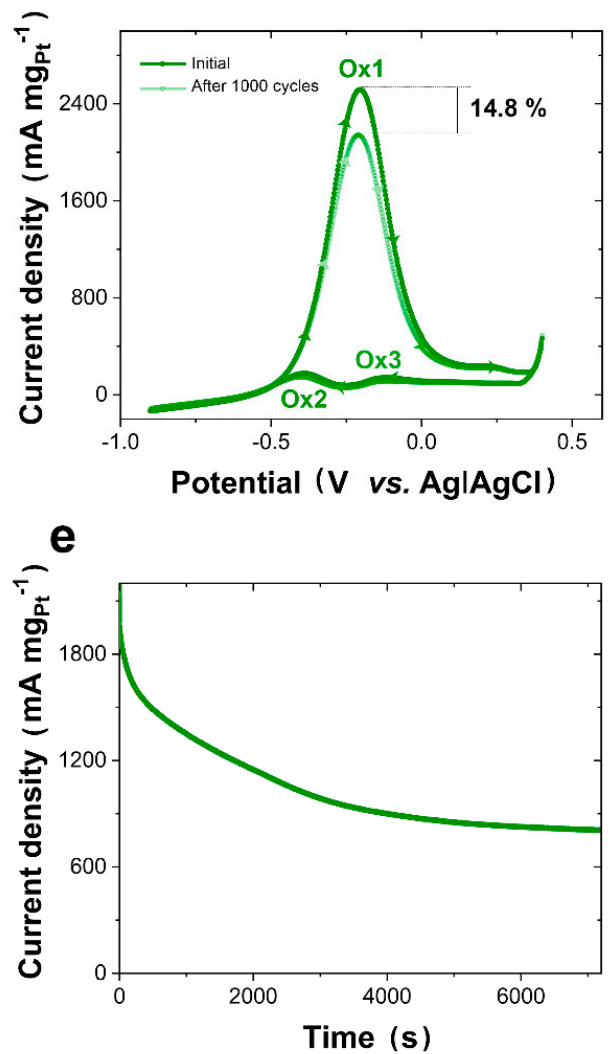

b

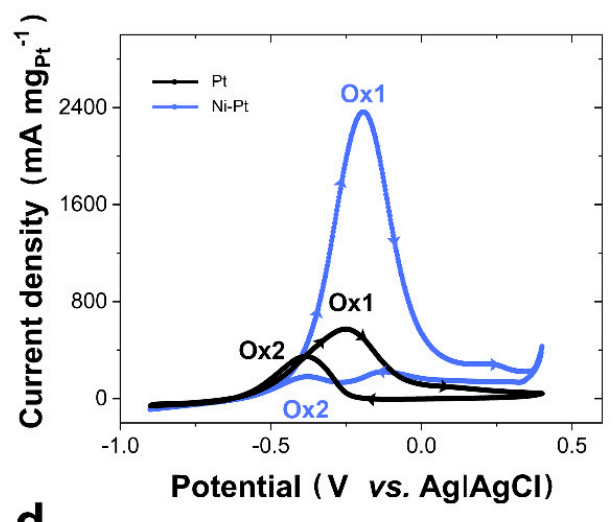

d

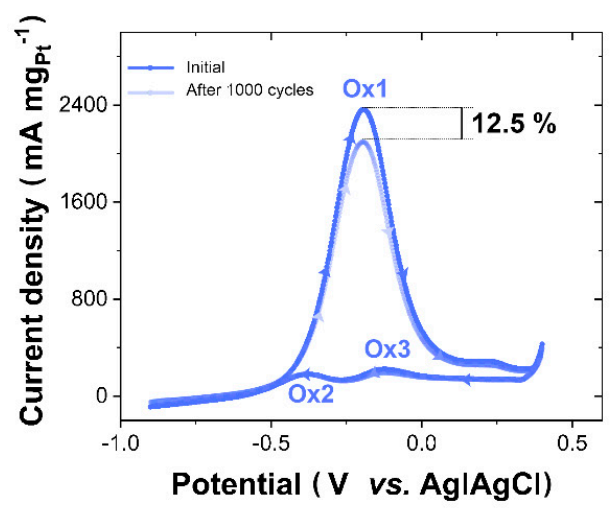

f

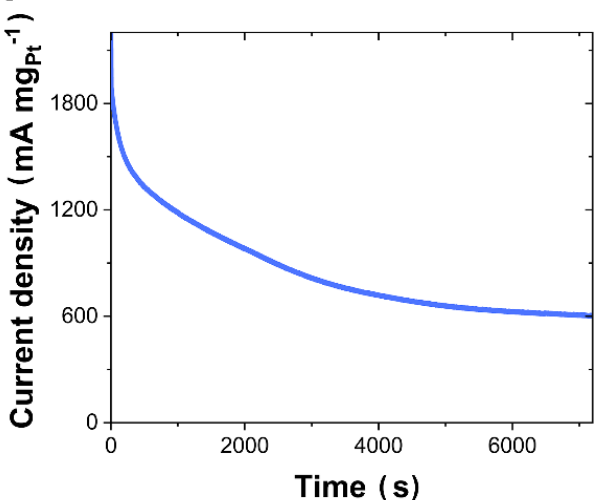

Figure 7. Cyclic voltammograms of methanol electro-oxidation in a solution containing $1 \mathrm{M}$ of $\mathrm{KOH}$ and $1 \mathrm{M}$ of methanol at a scan rate of $50 \mathrm{mV} \mathrm{s}^{-1}$ for Pt and Ni-rich Ni-Pt mesoporous films electrodeposited on (a) FTO and (b) Si/Ti/Au substrates. Cyclic voltammograms of methanol electro-oxidation in a solution containing $1 \mathrm{M}$ of $\mathrm{KOH}$ and $1 \mathrm{M}$ of methanol at a scan rate of $50 \mathrm{mV} \mathrm{s}^{-1}$ before and after 1000 cycles for Ni-rich Ni-Pt mesoporous films deposited on (c) FTO and (d) Si/Ti/Au substrates, along with chronoamperometric curves recorded at $-0.15 \mathrm{~V}$ versus $\mathrm{Ag} \mid \mathrm{AgCl}$ for $7200 \mathrm{~s}$ for Ni-rich Ni-Pt mesoporous films deposited on (e) FTO and (f) Si/Ti/Au substrates. $\mathrm{T}=25^{\circ} \mathrm{C}$. 
Table 3. Catalytic performance of Pt-based electrocatalysts for methanol electro-oxidation in a solution containing $1 \mathrm{M}$ of $\mathrm{KOH}$ and $1 \mathrm{M}$ of methanol at a scan rate of $50 \mathrm{mV} \mathrm{s}^{-1}$.

\begin{tabular}{ccccccc}
\hline System & $E_{\text {onset }}(\mathbf{V})$ & $\boldsymbol{E} \boldsymbol{p}(\mathbf{V})$ & $j_{\mathbf{f}}\left(\mathbf{m A ~ c m} \mathbf{~ c m}^{-2}\right)$ & $j_{\mathbf{f}}\left(\mathbf{m A ~ m g} \mathbf{~ m t}^{-1}\right)$ & $j_{\mathbf{f}} / j_{\mathbf{b}}$ & References \\
\hline Pt on FTO-coated glass & -0.588 & -0.251 & 8.5 & 664 & 1.7 & This work \\
Pt on Si/Ti/Au & -0.594 & -0.248 & 7.4 & 573 & 1.6 & This work \\
Ni-Pt on FTO-coated glass & -0.613 & -0.207 & 10.1 & 2546 & 14.9 & This work \\
Ni-Pt on Si/Ti/Au & -0.501 & -0.192 & 9.4 & 2364 & 16.8 & This work \\
Pt-Co NF & - & - & - & 4280 & - & {$[48]$} \\
Pt-BiOI/MoS & -0.582 & -0.196 & - & 1007 & 1.3 & {$[49]$} \\
Pt/g-C ${ }_{3} \mathrm{~N}_{4} / \mathrm{MoS}_{2}$ & -0.646 & -0.194 & - & 1618 & 2.8 & {$[50]$} \\
Pt-2D Fe $\mathrm{O}_{3}$ & -0.412 & -0.184 & - & 343 & 2.5 & {$[51]$} \\
Pt-Ag/G & -0.462 & -0.069 & - & 5628 & 5.6 & {$[52]$} \\
Pt-doped Ni(OH) 2 & -0.581 & 0.058 & - & 1356 & 5.6 & {$[53]$} \\
Pt-CoOOH-CDs/C & -0.578 & -0.205 & - & 856 & 4.52 & {$[54]$}
\end{tabular}

\section{Conclusions}

Bimetallic Ni-rich Ni-Pt mesoporous films, which demonstrate highly accessible active surface sites, were synthetized via simple block copolymer-templated electrochemical deposition and tested as efficient electrocatalysts for methanol electro-oxidation in alkaline conditions. The possibilities and potential limitations of block copolymer-templated electrodeposition of metallic mesoporous films on two different typical working electrodes (i.e., FTO and Si/Ti/Au) were clarified by analyzing the role of each of the solution's component and the applied potential on the pore definition. The experiments revealed that both the THF (when used as it is not necessary for all of the block copolymers) and the block copolymer electropolymerization can be significantly promoted depending on the nature of the substrate; this can be beneficial or detrimental if it is removed, depending on the deposition efficiency, for the formation of a well-defined mesoporous 3D network. Among other findings, the nature of the metallic precursor has been proven to be crucial for allowing the interaction of the hydrophilic micellar portion and the metal complex. The global charge density of micelles-metal complex should be positive to promote their electrostatic attraction to the working electrode surface. The mesoporous metallic deposition was undertaken with the initial deposition of the copolymer and platinum, the presence of which favors the consequent codeposition of nickel. The process was also accompanied by a simultaneous hydrogen evolution, related to the necessarily high proton concentration and promoted by the metallic Ni-rich Ni-Pt material. By varying the applied potential, Ni-Pt deposits with a Ni content of $65-75 \%$ and a mesoporous structure with a pore size between 20 and $35 \mathrm{~nm}$ were attained. The resulting mesoporous films exhibited an exceptionally effective surface area of $65 \mathrm{~m}^{2} \mathrm{~g}^{-1}$ on average, which presents conditions that are favorable for reactants to have maximum access to active sites, thereby highlighting them as potential candidates for electrocatalysis. Lastly, the electrochemical oxidation of methanol in an alkaline medium was analyzed in order to test the electrocatalytical performance of the aforementioned mesoporous films. The voltammetric characterization of the process revealed that the oxidation of methanol could occur over a wide range of potentials without detecting the typical inhibitory effect of the oxidation reaction intermediates, which is typically the most deleterious effect that occurs on pure platinum structures. Potentiostatic experiments conducted with the more positive potentials confirmed the stationary current value recorded in long-term experiments, which demonstrates the promising stability and durability of the prepared materials for MOR.

Supplementary Materials: The following are available online at http://www.mdpi.com/2079-4991/10/8/1435/s1, Figure S1: XPS spectra of deposits obtained using Ni (Bath 3) solution on FTO-coated glass at -1.3 V (vs. Ag|AgCl) after circulating $7.5 \mathrm{C} \mathrm{cm}^{-2}$; Figure S2: FE-SEM micrographs of the deposits obtained using Ni (Bath 3) solution on FTO-coated glass at $-1.3 \mathrm{~V}$ (vs. $\mathrm{Ag} \mid \mathrm{AgCl}$ ) after circulating $7.5 \mathrm{C} \mathrm{cm}^{-2}$ and being subjected to a $45 \mathrm{~min} \mathrm{O}_{2}$ plasma treatment; Figure S3: FE-SEM micrographs of the deposits obtained using Ni (Bath 3) solution Si/Ti/Au substrates at $-1.3 \mathrm{~V}$ (vs. Ag|AgCl) after circulating $7.5 \mathrm{C} \mathrm{cm}^{-2}$; and Figure S4: FE-SEM micrographs of the deposits obtained using Ni-Pt (Bath 4) solution on (a) FTO-coated glass and (b) Si/Ti/Au substrates at -1.2 V (vs. $\mathrm{Ag} \mid \mathrm{AgCl}$ ) after circulating $7.5 \mathrm{C} \mathrm{cm}^{-2}$. Figure S5: FE-SEM micrographs and XRD patterns of the deposits obtained using Ni-Pt (Bath 4) solution on FTO-coated glass and Si/Ti/Au substrates at $-1.3 \mathrm{~V}$ (vs. Ag|AgCl) after 1000 cycling experiments. 
Author Contributions: Conceptualization, A.S., E.G. and L.P.; methodology, R.A. and A.S.; validation, A.S., E.G. and L.P.; formal analysis, A.S., E.G. and L.P.; investigation, R.A. and A.S.; resources, E.G. and L.P.; data curation, R.A. and A.S.; writing - original draft preparation, R.A. and A.S.; writing-review and editing, A.S., E.G., L.P. and J.M.; visualization, A.S.; supervision, A.S., E.G. and L.P.; project administration, A.S. and L.P.; funding acquisition, E.G. and L.P. All authors have read and agreed to the published version of the manuscript.

Funding: This work was supported by the Metrohm foundation and the TEC2017-85059-C3-2-R projects (co-financed by the Fondo Europeo de Desarrollo Regional, FEDER) from the Spanish Ministerio de Economía y Competitividad (MINECO).

Acknowledgments: Albert Serrà would like to acknowledge funding from the EMPAPOSTDOCS-II program. The EMPAPOSTDOCS-II programme has received funding from the European Union's Horizon 2020 research and innovation programme under the Marie Skłodowska-Curie grant agreement number 754364.

Conflicts of Interest: The authors declare no conflict of interest.

\section{References}

1. Axon, S.; James, D. The UN Sustainable Development Goals: How can sustainable chemistry contribute? A view from the chemical industry. Curr. Opin. Green Sustain. Chem. 2018, 13, 140-145. [CrossRef]

2. Bilgili, F.; Koçak, E.; Bulut, Ü. The dynamic impact of renewable energy consumption on $\mathrm{CO}_{2}$ emissions: A revisited Environmental Kuznets Curve approach. Renew. Sustain. Energy Rev. 2016, 54, 838-845. [CrossRef]

3. Huisingh, D.; Zhang, Z.; Moore, J.C.; Qiao, Q.; Li, Q. Recent advances in carbon emissions reduction: Policies, technologies, monitoring, assessment and modeling. J. Clean. Prod. 2015, 103, 1-12. [CrossRef]

4. Bashir, S.; Hanumandla, P.; Huang, H.Y.; Liu, J.L. Nanostructured materials for advanced energy conversion and storage devices: Safety implications at end-of-life disposal. Nanostructured Mater. Next Gener. Energy Storage Convers. Fuel Cells 2018, 4, 517-542. [CrossRef]

5. Staffell, I.; Scamman, D.; Velazquez Abad, A.; Balcombe, P.; Dodds, P.E.; Ekins, P.; Shah, N.; Ward, K.R. The role of hydrogen and fuel cells in the global energy system. Energy Environ. Sci. 2019, 12, 463-491. [CrossRef]

6. Kamarudin, S.K.; Achmad, F.; Daud, W.R.W. Overview on the application of direct methanol fuel cell (DMFC) for portable electronic devices. Int. J. Hydrogen Energy 2009, 34, 6902-6916. [CrossRef]

7. Lei, W.; Li, M.; He, L.; Meng, X.; Mu, Z.; Yu, Y.; Ross, F.M.; Yang, W. A general strategy for bimetallic Pt-based nano-branched structures as highly active and stable oxygen reduction and methanol oxidation bifunctional catalysts. Nano Res. 2020, 13, 638-645. [CrossRef]

8. Junoh, H.; Jaafar, J.; Nik Abdul, N.A.H.; Ismail, A.F.; Othman, M.H.D.; Rahman, M.A.; Aziz, F.; Yusof, N. Performance of polymer electrolyte membrane for direct methanol fuel cell application: Perspective on morphological structure. Membranes (Basel) 2020, 10, 34. [CrossRef]

9. Huang, W.; Wang, H.; Zhou, J.; Wang, J.; Duchesne, P.N.; Muir, D.; Zhang, P.; Han, N.; Zhao, F.; Zeng, M.; et al. Highly active and durable methanol oxidation electrocatalyst based on the synergy of platinum-nickel hydroxide-graphene. Nat. Commun. 2015, 6, 1-8. [CrossRef]

10. Pongpichayakul, N.; Waenkeaw, P.; Jakmunee, J.; Themsirimongkon, S.; Saipanya, S. Activity and stability improvement of platinum loaded on reduced graphene oxide and carbon nanotube composites for methanol oxidation. J. Appl. Electrochem. 2020, 50, 51-62. [CrossRef]

11. Chen, G.; Dai, Z.; Bao, H.; Zhang, L.; Sun, L.; Shan, H.; Liu, S.; Ma, F. Enhanced Anti-CO poisoning of platinum on mesoporous carbon spheres by abundant hydroxyl groups in methanol electro-oxidation. Electrochim. Acta 2020, 336, 135751. [CrossRef]

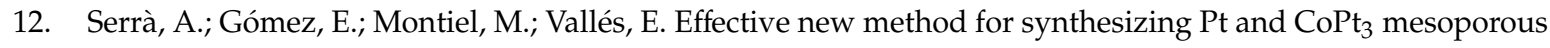
nanorods. New catalysts for ethanol electro-oxidation in alkaline medium. RSC Adv. 2016, 6. [CrossRef]

13. Erukhimovich, I.; de la Cruz, M.O. Phase equilibria and charge fractionation in polydisperse polyelectrolyte solutions. J. Polymer Sci. 2004, 2201-2225. [CrossRef]

14. Huang, L.; Zhang, X.; Wang, Q.; Han, Y.; Fang, Y.; Dong, S. Shape-Control of Pt-Ru Nanocrystals: Tuning Surface Structure for Enhanced Electrocatalytic Methanol Oxidation. J. Am. Chem. Soc. 2018, 140, 1142-1147. [CrossRef]

15. Serrà, A.; Montiel, M.; Gómez, E.; Vallés, E. Electrochemical synthesis of mesoporous CoPt nanowires for methanol oxidation. Nanomaterials 2014, 4, 189-202. [CrossRef]

16. Zhong, J.; Sun, M.; Xiang, S.; Fan, Y.; Waqas, M.; Huang, K.; Tang, Y.; Chen, W.; Yang, J. Sulfonated cobalt phthalocyanine-derived $\mathrm{Co}-\mathrm{N}-\mathrm{S}$ tridoped carbon nanotubes as platinum catalyst supports for highly efficient methanol electrooxidation. Appl. Surf. Sci. 2020, 511, 145519. [CrossRef] 
17. Zhong, J.P.; Hou, C.; Li, L.; Waqas, M.; Fan, Y.J.; Shen, X.C.; Chen, W.; Wan, L.Y.; Liao, H.G.; Sun, S.G. A novel strategy for synthesizing $\mathrm{Fe}, \mathrm{N}$, and $\mathrm{S}$ tridoped graphene-supported $\mathrm{Pt}$ nanodendrites toward highly efficient methanol oxidation. J. Catal. 2020, 381, 275-284. [CrossRef]

18. Du, X.; Luo, S.; Du, H.; Tang, M.; Huang, X.; Shen, P.K. Monodisperse and self-assembled Pt-Cu nanoparticles as an efficient electrocatalyst for the methanol oxidation reaction. J. Mater. Chem. A 2016, 4, 1579-1585. [CrossRef]

19. Amin, R.S.; Abdel Hameed, R.M.; El-Khatib, K.M.; Elsayed Youssef, M. Electrocatalytic activity of nanostructured $\mathrm{Ni}$ and $\mathrm{Pd}-\mathrm{Ni}$ on Vulcan XC-72R carbon black for methanol oxidation in alkaline medium. Int. J. Hydrogen Energy 2014, 39, 2026-2041. [CrossRef]

20. Serrà, A.; Gómez, E.; Golosovsky, I.V.; Nogués, J.; Vallés, E. Effective ionic-liquid microemulsion based electrodeposition of mesoporous $\mathrm{Co}-\mathrm{Pt}$ films for methanol oxidation catalysis in alkaline media. J. Mater. Chem. A 2016, 4, 7805-7814. [CrossRef]

21. Franceschini, E.A.; Bruno, M.M.; Williams, F.J.; Viva, F.A.; Corti, H.R. High-activity mesoporous Pt/Ru catalysts for methanol oxidation. ACS Appl. Mater. Interfaces 2013, 5, 10437-10444. [CrossRef] [PubMed]

22. Serrà, A.; Vallés, E. Microemulsion-based one-step electrochemical fabrication of mesoporous catalysts. Catalysts 2018, 8, 395. [CrossRef]

23. Liu, D.; Zhang, L.; Lv, P. Facile synthesis of ordered mesoporous carbon monolith with close-packed microspheres structure through emulsion templating. Microporous Mesoporous Mater. 2020, 297, 110056. [CrossRef]

24. Li, C.; Jiang, B.; Wang, Z.; Li, Y.; Hossain, M.S.A.; Kim, J.H.; Takei, T.; Henzie, J.; Dag, Ö.; Bando, Y.; et al. First Synthesis of Continuous Mesoporous Copper Films with Uniformly Sized Pores by Electrochemical Soft Templating. Angew. Chem. Int. Ed. 2016, 55, 12746-12750. [CrossRef] [PubMed]

25. Baba, D.; Li, C.; Malgras, V.; Jiang, B.; Alamri, H.R.; Alothman, Z.A.; Hossain, M.S.A.; Yamauchi, Y.; Asahi, T. Fabrication of Mesoporous $\mathrm{Cu}$ Films on $\mathrm{Cu}$ Foils and Their Applications to Dopamine Sensing. Chem. Asian J. 2017, 12, 2467-2470. [CrossRef]

26. Kang, Y.; Jiang, B.; Alothman, Z.A.; Badjah, A.Y.; Naushad, M.; Habila, M.; Wabaidur, S.; Henzie, J.; Li, H.; Yamauchi, Y. Mesoporous PtCu Alloy Nanoparticles with Tunable Compositions and Particles Sizes Using Diblock Copolymer Micelle Templates. Chem. Eur. J. 2019, 25, 343-348. [CrossRef]

27. Stein, A.; Schroden, R.C. Colloidal crystal templating of three-dimensionally ordered macroporous solids: Materials for photonics and beyond. Curr. Opin. Solid State Mater. Sci. 2001, 5, 553-564. [CrossRef]

28. Li, Z.; Yang, L.; Li, Y.; Yang, Y.; Zhou, C.; Ding, Y.; Zhao, J.; Li, Y. Effects of pore size on the mechanical properties of three-dimensionally ordered macroporous nickel. Mater. Des. 2013, 45, 52-55. [CrossRef]

29. Lahiri, A.; Chutia, A.; Carstens, T.; Endres, F. Surface-oxygen induced electrochemical self-assembly of mesoporous conducting polymers for electrocatalysis. J. Electrochem. Soc. 2020. [CrossRef]

30. Mawhinney, K.; Jana, S.C. Design Of Emulsion-Templated Mesoporous-Macroporous Polyurea Gels and Aerogels. ACS Appl. Polym. Mater. 2019, 1, 3115-3129. [CrossRef]

31. Jin, L.; Liu, B.; Louis, M.E.; Li, G.; He, J. Highly Crystalline Mesoporous Titania Loaded with Monodispersed Gold Nanoparticles: Controllable Metal-Support Interaction in Porous Materials. ACS Appl. Mater. Interfaces 2020, 12, 9617-9627. [CrossRef] [PubMed]

32. Tkachenko, V.; Matei Ghimbeu, C.; Vaulot, C.; Josien, L.; Vidal, L.; Poly, J.; Chemtob, A. Diblock Copolymer Core-Shell Nanoparticles as Template for Mesoporous Carbons: Independent Tuning of Pore Size and Pore Wall Thickness. Langmuir 2019, 35, 16324-16334. [CrossRef] [PubMed]

33. Renner, F.U.; Ankah, G.N.; Bashir, A.; Ma, D.; Biedermann, P.U.; Shrestha, B.R.; Nellessen, M.; Khorashadizadeh, A.; Losada-Pérez, P.; Duarte, M.J.; et al. Star-Shaped Crystallographic Cracking of Localized Nanoporous Defects. Adv. Mater. 2015, 27, 4877-4882. [CrossRef] [PubMed]

34. Vega, A.A.; Newman, R.C. Nanoporous Metals Fabricated through Electrochemical Dealloying of Ag-Au-Pt with Systematic Variation of Au:Pt Ratio. J. Electrochem. Soc. 2014, 161, C1-C10. [CrossRef]

35. Lahiri, A.; Endres, F. Review-Electrodeposition of Nanostructured Materials from Aqueous, Organic and Ionic Liquid Electrolytes for Li-Ion and Na-Ion Batteries: A Comparative Review. J. Electrochem. Soc. 2017, 164, D597-D612. [CrossRef]

36. Serrà, A.; Vallés, E. Advanced electrochemical synthesis of multicomponent metallic nanorods and nanowires: Fundamentals and applications. Appl. Mater. Today 2018, 12, 207-234. [CrossRef]

37. Baba, D.; Kim, J.; Henzie, J.; Li, C.; Jiang, B.; Dag, Ö.; Yamauchi, Y.; Asahi, T. Electrochemical deposition of large-sized mesoporous nickel films using polymeric micelles. Chem. Commun. 2018, 54, 10347-10350. [CrossRef] 
38. Nugraha, A.S.; Na, J.; Hossain, M.S.A.; Lin, J.; Kaneti, Y.V.; Iqbal, M.; Jiang, B.; Bando, Y.; Asahi, T.; Yamauchi, Y. Block copolymer-templated electrodeposition of mesoporous Au-Ni alloy films with tunable composition. Appl. Mater. Today 2020, 18, 100526. [CrossRef]

39. Palma-Cando, A.; Rendón-Enríquez, I.; Tausch, M.; Scherf, U. Thin functional polymer films by electropolymerization. Nanomaterials 2019, 9, 1125. [CrossRef]

40. Hernández-Ferrer, J.; Ansón-Casaos, A.; Martínez, M.T. Electrochemical synthesis and characterization of single-walled carbon nanotubes/polypyrrole films on transparent substrates. Electrochim. Acta 2012, 64, 1-9. [CrossRef]

41. Jeong, G.H.; Kim, S.J.; Ko, H.S.; Han, E.M.; Park, K.H. Electrochemical Properties of Graphene/PEDOT:PSS Counter Electrode in Dye-sensitized Solar Cells. Mol. Cryst. Liq. Cryst. 2015, 620, 117-122. [CrossRef]

42. Eiler, K.; Suriñach, S.; Sort, J.; Pellicer, E. Mesoporous Ni-rich Ni-Pt thin films: Electrodeposition, characterization and performance toward hydrogen evolution reaction in acidic media. Appl. Catal. B Environ. 2020, 265, 118597. [CrossRef]

43. Zhang, J.; Quintana, A.; Menéndez, E.; Coll, M.; Pellicer, E.; Sort, J. Electrodeposited Ni-Based Magnetic Mesoporous Films as Smart Surfaces for Atomic Layer Deposition: An "all-Chemical" Deposition Approach toward 3D Nanoengineered Composite Layers. ACS Appl. Mater. Interfaces 2018, 10, 14877-14885. [CrossRef] [PubMed]

44. Zou, Y.; Zhou, X.; Ma, J.; Yang, X.; Deng, Y. Recent advances in amphiphilic block copolymer templated mesoporous metal-based materials: Assembly engineering and applications. Chem. Soc. Rev. 2020, 49, 1173-1208. [CrossRef] [PubMed]

45. Maksic, A.; Rakocevic, Z.; Smiljanic, M.; Nenadovic, M.; Strbac, S. Methanol oxidation on Pd/Pt(poly) in alkaline solution. J. Power Sources 2015, 273, 724-734. [CrossRef]

46. Tripkovi, A.V.; Popovi, K.D.; Grgur, B.N.; Blizanac, B.; Ross, P.N.; Markovi, N.M. Methanol electrooxidation on supported Pt and PtRu catalysts in acid and alkaline solutions. Electrochim. Acta 2002, 47, 3707-3714. [CrossRef]

47. Cohen, J.L.; Volpe, D.J.; Abruña, H.D. Electrochemical determination of activation energies for methanol oxidation on polycrystalline platinum in acidic and alkaline electrolytes. Phys. Chem. Chem. Phys. 2007, 9, 49-77. [CrossRef]

48. Chen, S.; Li, M.; Gao, M.; Jin, J.; Van Spronsen, M.A.; Salmeron, M.B.; Yang, P. High-Performance Pt-Co Nanoframes for Fuel-Cell Electrocatalysis. Nano Lett. 2020, 20, 1974-1979. [CrossRef]

49. Zhang, H.; Zhai, C.; Yang, P.; Yuan, C.; Fu, N.; Zhu, M. In Situ Growth of BiOI/MoS2 Heterostructure as Pt Supports for Visible Light-Assisted Electrocatalytic Methanol Oxidation Reaction. Energy Technol. 2020, 8 , 1-8. [CrossRef]

50. Zhai, C.; Sun, M.; Zeng, L.; Xue, M.; Pan, J.; Du, Y.; Zhu, M. Construction of Pt/graphitic $\mathrm{C}_{3} \mathrm{~N}_{4} / \mathrm{MoS}_{2}$ heterostructures on photo-enhanced electrocatalytic oxidation of small organic molecules. Appl. Catal. B Environ. 2019, 243, 283-293. [CrossRef]

51. Hu, S.; Jiang, L.; Wang, B.; Ma, Y. Enhanced electrocatalytic methanol oxidation properties by photo-assisted $\mathrm{Fe}_{2} \mathrm{O}_{3}$ nanoplates. Int. J. Hydrogen Energy 2019, 44, 13214-13220. [CrossRef]

52. Shafaei Douk, A.; Saravani, H.; Noroozifar, M. One-pot synthesis of ultrasmall Pt-Ag nanoparticles decorated on graphene as a high-performance catalyst toward methanol oxidation. Int. J. Hydrogen Energy 2018, 43, 7946-7955. [CrossRef]

53. Yuan, G.; Wang, L.; Zhang, X.; Wang, Q. Self-supported Pt nanoflakes-doped amorphous $\mathrm{Ni}(\mathrm{OH})_{2}$ on $\mathrm{Ni}$ foam composite electrode for efficient and stable methanol oxidation. J. Colloid Interface Sci. 2019, 536, 189-195. [CrossRef] [PubMed]

54. Tu, W.; Sun, Y.; Wu, D.; Wang, H.; Huang, H.; Shao, M.; Liu, Y.; Kang, Z. Cobalt oxyhydroxide and carbon dots modified by platinum as superior electrocatalyst for methanol oxidation. Mater. Chem. Phys. 2019, 225, 64-71. [CrossRef]

55. Jamil, R.; Sohail, M.; Baig, N.; Ansari, M.S.; Ahmed, R. Synthesis of Hollow Pt-Ni Nanoboxes for Highly Efficient Methanol Oxidation. Sci. Rep. 2019, 9, 1-13. [CrossRef]

56. Tarrús, X.; Montiel, M.; Vallés, E.; Gómez, E. Electrocatalytic oxidation of methanol on CoNi electrodeposited materials. Int. J. Hydrogen Energy 2014, 39, 6705-6713. [CrossRef]

(C) 2020 by the authors. Licensee MDPI, Basel, Switzerland. This article is an open access article distributed under the terms and conditions of the Creative Commons Attribution (CC BY) license (http://creativecommons.org/licenses/by/4.0/). 